\title{
Mit 1 Wisch keimfrei
}

Mit den FD 366 sensitive wipes stellt Dürr aus Bietigheim-Bissingen gebrauchsfertige Desinfektionstücher als weiteren Teil der Dürr System-Hygiene vor. Die weichen, fein strukturierten Tücher sind fusselfrei und nicht

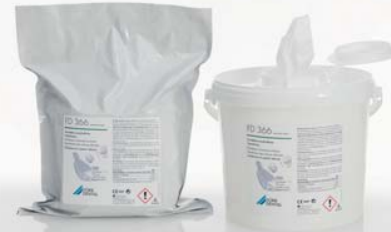
kratzend. In Verbindung mit der alkoholminimierten Tränklösung FD 366 sensitive erzielen sie

den besten materialschonenden Effekt. Gleichzeitig entfalten sie ihre volle desinfizierende Wirkung bereits nach einer Einwirkzeit von nur 1 min nach VAH. Die extragroßen Tücher ( 30 x $20 \mathrm{~cm}$ ) eignen sich besonders zur Schnelldesinfektion empfindlicher Oberflächen von Medizin- produkten, wie Kunststoffe und Acrylglas. Ebenso schonend desinfizieren sie die gesamte Behandlungseinheit inklusive der Kunstlederbezüge oder Geräteabdeckungen. Das Praxispersonal kann die Desinfektionstücher unter anderem für die Bedienfelder von Behandlungseinheiten und Geräte benutzen oder Hand- und Winkelstücke vor deren Aufbereitung nach Herstellerangaben desinfizieren.

Auch das breite Wirkungsspektrum überzeugt - denn die Desinfektionstücher basieren auf einer effektiven Kombination von Alkoholen und quartären Ammoniumverbindungen. Die Formel wirkt bakterizid, tuberkulozid, levurozid und begrenzt viruzid gegen behüllte Viren. Darüber hinaus bekämpft die Lösung unbehüllte Viren wie beispielsweise das NoroVirus.

Nach einer Presseinformation der Dürr Dental AG, Bietigheim-Bissingen www.duerrdental.com 